\title{
Hermenéutica y ciencias sociales: a propósito del vínculo entre la interpretación de la narración de Paul Ricoeur y el enfoque de investigación biográfico-narrativo*
}

\author{
Rodrigo Moreno Aponte**
}

Recibido: 12 de agosto de 2016 - Aprobado: 19 de septiembre de 2016

\section{Resumen}

Este trabajo aborda la relación entre la hermenéutica y las ciencias humanas. En la introducción presentamos el panorama de heterogeneidad de conceptos, planteamientos y posturas críticas acerca de la primera. Ante este escenario, donde la hermenéutica está en revisión y construcción constante, el escrito se focaliza en sustentar cómo se relacionan las ideas de uno de los grandes referentes de la hermenéutica, Paul Ricoeur, con el enfoque de investigación cualitativa biográfica-narrativa. Para tal fin, dividimos el texto en cuatro partes. En principio, por medio de las ideas del filósofo francés, exponemos cómo las características del texto escrito y los elementos que lo hacen susceptible de ser interpretado se pueden llevar a la acción humana, y por ende, a la investigación que es propia de las ciencias humanas. En segundo lugar, presentamos las características esenciales del enfoque biográfico-narrativo, por medio de las diferencias respecto al enfoque biográfico. En la tercera parte, traemos las ideas de Ricoeur acerca de la narración, a la vez que las vinculamos con el enfoque de investigación cualitativa en el que se centra este escrito. Finalmente, planteamos las conclusiones.

Palabras clave: hermenéutica, investigación cualitativa, biográfico-narrativo, Ricoeur, narración.

Este es un artículo de reflexión que surge como complemento de la metodología de mi tesis doctoral, titulada Pedagogía hermenéutica del lugar. Narrativas del exterior urbano de la escuela en su vínculo con el desarrollo de la alteridad en la acción educativa. Esta investigación se llevó a cabo para la Universidad de Málaga, España. DOI: http://dx.doi. org/10.15332/s0120-8454.2017.0090.09

* Magíster en Filosofia, Pontificia Universidad Javeriana. Candidato a doctor en Educación, Universidad de Málaga (España). Correo electrónico: rodrigo.moreno81@yahoo.com 


\section{Hermeneutics and social sciences: on the relation between the interpretation of Paul Ricoeur's narration and the biographical-narrative research approach*}

Rodrigo Moreno Aponte**

\section{Abstract}

This paper deals with the relationship between hermeneutics and human sciences. The introduction presents the outlook of the heterogeneity of concepts, beliefs and critical stances. In the presence of a setting where hermeneutics is in constant construction and review, this text focuses on supporting how the ideas of one of the main models of hermeneutics (Paul Ricoeur) are related to the qualitative biographic-narrative investigation perspective. For that purpose, the text is divided into four stages. First of all, according to the French philosopher, it is exposed how the characteristics of the written text and the elements that makes it liable for being performed can lead to human action and therefore to the typical investigation of human science. Second, we present the essential characteristics of the biographic-narrative perspective through the differences regarding the biographic perspective. In the third section, we bring Ricoeur's ideas about narrative linked with the qualitative research perspective. Finally, we set out the conclusions.

Keywords: Hermeneutics, qualitative research, biographic-narrative, Ricoeur, narrative.

This is a reflection article that comes as a complement to the methodology of my doctoral thesis, entitled Hermeneutic Pedagogy of the place. Narratives of the urban exterior of the school in its connection with the development of alterity in educational action. This research was carried out for the University of Malaga, Spain. DOI: http://dx.doi.org/10.15332/ s0120-8454.2017.0090.09

* Master in Philosophy, Pontificia Universidad Javeriana. PhD candidate in Education, University of Málaga (Spain). Email: rodrigo. moren081@yahoo.com 


\section{Herméneutique et sciences sociales: à propos du lien entre l'interprétation de la narration de Paul Ricoeur et le point de vue de la recherche biographique - narrative ${ }^{*}$}

Rodrigo Moreno Aponte*

\section{Résumé}

Ce travail aborde la relation entre l'herméneutique et les sciences humaines. Dans l'introduction nous présentons la situation d'hétérogénéité de concepts, de lignes de conduites et de postures critiques à propos de la première. Face à ce scénario, où l'herméneutique est en révision et en permanente construction, l'article met l'accent sur l'explication de comment les idées de l'une des grandes références de l'herméneutique, Paul Ricœur, ont un lien avec le point de vue de la recherche qualitative biographique - narrative. Dans ce but, nous divisons le texte en quatre parties. Tout d'abord, nous exposons à travers les idées du philosophe français, comment les caractéristiques du texte et les éléments qui le font susceptible d'être interprété peuvent se transposer à l'action humaine, et par conséquent, à la recherche qui est propre des sciences humaines. En deuxième lieu, nous présentons les caractéristiques essentielles du point de vue biographique - narratif, au moyen des différences par rapport au point de vue biographique. Dans la troisième partie, nous exposons les idées de Ricœur à propos de la narration, à la fois que nous les lions avec le point de vue de la recherche qualitative sur lequel se concentre cet article. Finalement, nous présentons les conclusions.

Mots clés: Herméneutique, recherche qualitative, biographique-narratif, Ricœur, narration.

Cet article de réflexion surgit comme complément de la méthodologie de ma thèse doctorale, intitulée Pédagogie herméneutique du lieu. Narrations de l'extérieur urbain de l'école dans son lien avec le développement de l'altérité dans I'action éducative. Cette recherche a été réalisée pour l'Université de Malaga, Espagne. DOI: http://dx.doi.org/10.15332/ s0120-8454.2017.0090.09

* Magister en Philosophie, Pontificia Universidad Javeriana. Candidat à docteur en Éducation, Université de Malaga (Espagne). Email: rodrigo.moreno81@yahoo.com 


\section{Introducción}

La hermenéutica es un campo que no deja indiferente a quienes se encuentran, por alguna razón, con sus planteamientos. Su panorama se complejiza cuando sus desarrollos conceptuales son llevados al campo de las ciencias sociales y la investigación cualitativa que subyace a esta. Se pueden encontrar elementos de la hermenéutica en métodos para acceder al conocimiento de las ciencias sociales, como son el estudio de caso, la cartografía social, la etnografía, la fenomenología, la teoría fundamentada, la investigación acción participativa y las narrativas (Ángel, 2011).

Cabe anotar que no podemos hablar de una sola hermenéutica. Dos de sus máximos representantes en el siglo XX, Ricoeur y Gadamer, tienen objetivos y formas distintas de darle nombre a su proyecto hermenéutico. El primero usa la denominación, hermenéutica-fenomenológica, puesto que no renuncia del todo al proceso de reducción ni a la cuestión metodológica, además se enfoca en la interpretación. El segundo prefiere usar el término hermenéutica filosófica, pues busca una teoría filosófica consagrada a las ciencias humanas, y su foco de atención es la comprensión (Grondín, 2009).

Si hablamos concretamente de una hermenéutica vista desde Gadamer, no podemos decir que estos planteamientos son propuestos tal y como lo hacen las ciencias humanas. Herrera (2009) explica que no se puede entender la hermenéutica filosófica como una asimilación a las investigaciones en ciencia social. Más bien, lo que plantea el filósofo colombiano es que una perspectiva hermenéutica permite que las ciencias se piensen a sí mismas y sus prácticas de investigación. Pero tampoco se deja de admitir que esta

[...] desarrolla el tema de la comprensión, como rasgo esencial de la existencia humana, y en su reflexión sobre lo que, en la tradición alemana, se conoce como 'las ciencias del espíritu', las ciencias sociales contemporáneas pueden hallar la posibilidad de comprenderse más allá del horizonte positivista. (Herrera, 2009, pp. 103-104)

Los conceptos de la filosofía hermenéutica invitan a las ciencias sociales a comprender qué es eso que se quiere comprender. Pero también ese comprender debe ir en la vía de poder dar a entender lo que se ha comprendido. Con respecto al componente hermenéutico de las ciencias sociales, Ávila (2012) plantea que:

para comprender el comprender hay que "parar orejas" y aprender a escuchar las voces acalladas, silenciadas o simplemente atoradas en las gargantas de las clases, las etnias, los géneros o las generaciones marginadas; para traducir el comprender hay que hacer oír las voces maliciosamente escondidas o distorsionadas, como también los gestos arbitrariamente vaciados de sentido" (p. 47). 
Este triple trabajo de la hermenéutica, unificador, comprensivo y de traducción, es un reto para la ciencia social porque exige por parte de los investigadores una reformulación constante de su quehacer y un estado de apertura a la vinculación de distintos saberes. Incluso, encontramos llamados a las ciencias sociales para que vinculen, ya no cuestiones de método, sino dimensiones del ser humano como la sabiduría y los saberes ancestrales, la ciencia y la tecnología, el espacio y el tiempo social y una perspectiva socio-ambiental (Molano, 2007). Es acá donde el campo de la tradición hermenéutica juega sus cartas para apoyar ese proceso de comprensión de lo humano.

La hermenéutica se enfrenta contra la idea de un sujeto que conoce y el objeto que es susceptible de ser conocido; o en otras palabras, se distancia de la conocida dicotomía sujeto-objeto de las ciencias exactas. Este llamado giro hermenéutico que se da en el siglo $X X$, supuso para las ciencias sociales un desplazamiento para acercar o distanciar posturas en torno a la pretensión de dominar cada parte de la realidad de los discursos de carácter empírico-analítico. Esto, traducido al plano de la investigación social, implica la posibilidad de revaluar la posición del intérprete y lo interpretado en el hecho social.

Esta ruptura de la hermenéutica con el positivismo supone una serie de decisiones metodológicas y de método para acceder a la comprensión de los fenómenos sociales. ¿Podemos dominar el hecho social acudiendo a nuestra objetividad sin dejarnos permear por esa realidad? ¿Deben mezclar los investigadores sociales su realidad con la del hecho social? ¿Pueden estar estos dos estadios presentes? Son preguntas que han estado en medio del debate y, a la vez, en el interior de las investigaciones en el campo de las ciencias humanas en la actualidad. En la primera pregunta encontramos esa vuelta al mundo de la vida cotidiana propuesto por Schütz (1972), en el que se llega a esta como un investigador que comparte ese mundo con los sujetos núcleos de la investigación.

El científico social concibe sus prácticas desde campos de actividad específicos y desde su participación en la vida cotidiana, lo cual conlleva la necesidad de ruptura y descentramientos epistémicos, a la vez que de ubicación de su trayectoria vital que se cruza con las trayectorias de aquellos con quienes convive como investigador o como actor cotidiano (Orozco, en Almario y Ruiz, 2008).

Este enfrentamiento ha llevado a distintas posturas alrededor de la hermenéutica. En el plano de la discusión están los que la acusan de inconmensurable por su presunta falta de rigor científico, y los que la consideran saberes particulares e incluso aislados. Otros, como Rorty, defienden que estas acusaciones desconocen el campo sobre el cuál se ocupa la hermenéutica. Desarrollos epistemológicos como los de Apel, encuentran a la hermenéutica como un punto común entre las ciencias naturales y las ciencias sociales, pero, con un matiz en el que esta debe tender a ser normativa para así acceder a parámetros de validez (Scivoletto, 2012). Por otro lado, están los planteamientos que afirman que la hermenéutica, de corte Gadameriano, se puede articular con los horizontes de las ciencias exactas (Gallego, citado en Cuartas, 2010). En un sentido similar a esto último 
se presenta la posibilidad de que la hermenéutica pueda ser instrumentalizada, claro está, si se tiene en cuenta que esto puede suceder "mientras no asuma el modelo científico-natural de la explicación causal nomológica y se reafirme en el reconocimiento de la historicidad del lenguaje y la condición contingente del enunciado sobre la verdad científica" (Castrillón, citado en Cuartas, 2010). Se plantean también propuestas que pretenden sustentar que la epistemología y la hermenéutica filosófica tienen criterios de racionalidad semejante, tanto para establecer lo conmensurable como para comprender lo conmensurable (FloresGalindo, 2009). Posturas conciliadoras evidencian que la influencia hermenéutica en las ciencias sociales invita a que se encuentre un punto medio en el que se llegue a un tipo de generalidad para que, de esta manera, se quite el mote del relativismo radical de la hermenéutica, tal y como afirma Betancur (2008):

En ciencias sociales no es cierto que todo vale. Los investigadores realizan constantes esfuerzos por demostrar que tal interpretación es mejor que otra y por demostrar mediante argumentos que la hipótesis de explicación/comprensión de los hechos que proponen es más adecuada que otras. Lo que se realiza constantemente en la cultura es la discusión racional de teorías que se someten a validación por las comunidades académicas. Es cierto que no se puede aspirar a la verdad absoluta o a la certeza de ninguna de ellas, pero como afirma Putnam, es lo que tenemos y no es poco. (p. 28)

Este panorama - aún en debate sobre la hermenéutica, y, nos atrevemos a decir, en continua construcción - de ninguna manera se puede considerar un defecto epistemológico. Por el contrario, esta puede ser la esencia misma de la hermenéutica. Recordemos la última frase que Gadamer usa en el paradigmático libro Verdad y método (1977): "Mal hermeneuta el que crea que puede o debe quedarse con la última palabra" (p. 673). Para las ciencias humanas esta no es solo la posibilidad de pensar una metodología, sino que conlleva la oportunidad de estarse sometiendo a un autoexamen y autorreflexión que le permitan comprender el horizonte de los fenómenos que busca estudiar, no como un saber totalizador, mucho menos fragmentario, sino más bien unificador.

Lo que pretendemos en este artículo es evidenciar, desde un marco general, cómo está presente en el discurso de las ciencias humanas la perspectiva hermenéutica; y, desde un referente particular, sustentar cómo se presenta el vínculo entre el proceso de interpretación y la investigación cualitativa. Ante el diverso y complejo panorama al que se enfrenta la hermenéutica, según se acabó de exponer, este artículo se centrará en la propuesta que Paul Ricoeur presenta en este campo para relacionarla con el enfoque de investigación biográfico-narrativo. Para este cometido, en primer lugar, se explicará cómo las características del texto escrito se aplican a la investigación social y, por ende, se puede establecer la relación entre hermenéutica y ciencias sociales. En segundo lugar, serán descritas las características centrales del enfoque biográfico-narrativo. Finalmente, se volverá Paul Ricoeur para realizar un acercamiento a su propuesta de interpretación narrativa que será vinculada, de paso, con el punto anterior. 


\section{Ricoeur y las ciencias sociales}

Ricoeur en su escrito, La acción considerada texto, sobre el cual anclaremos la exposición en este apartado, plantea que la relación entre ciencias humanas y hermenéutica está dada por los problemas que se suscitan en la segunda. Ahí, la interpretación de textos parte del texto escrito y no del lenguaje hablado. Afirma el hermeneuta francés que las ciencias humanas son hermenéuticas porque : “1) su objeto revela algunos rasgos constitutivos como texto, y 2) [...] su metodología desarrolla la misma clase de procedimientos que los de la Auslegung o interpretación de textos" (Ricoeur, 1985, p. 47). Frente a esto, se pregunta si se puede establecer la noción de texto como un paradigma pertinente al objeto de las ciencias humanas y, si a su vez, esta forma de interpretación de textos es acorde con aquel.

Para contestar estos interrogantes Ricoeur plantea que el discurso es el acontecimiento del lenguaje $y$, acudiendo a Benveniste, explica que el objeto de una lingüística del discurso es la oración. La lingüística del lenguaje va en un sentido distinto y se preocupa por el signo, a la manera de Saussure. El habla, como un acontecimiento, tendría entonces un carácter temporal en el que se pueden identificar tres eventos: 1) el sujeto que pronuncia; 2) siempre se refiere a algo, y 3) también se comunica a un interlocutor. Esto constituiría el habla como un acontecimiento.

En el lenguaje hablado la acción es fugaz, mientras que en la escritura hay algo que permanece fijado. El habla, al ser fugaz, puede ser fijada por medio del acto interpretativo. La escritura fijaría, no el acontecimiento en sí, puesto que es algo pasajero, sino lo que se dice en ese acontecimiento. Por lo tanto, se puede decir que la hermenéutica acude al acto de habla de ese acontecimiento que, en el sentido de Searle, evidencia tres funciones: un decir, lo locutivo; lo que hacemos al decir, lo ilocutivo; y los efectos de ese decir en la otra persona, lo perlocutivo. Esto afirma la idea de que el acto de habla excede la oración, y que cuando se exterioriza en el acto ilocutivo y perlocutivo se puede inscribir en la escritura.

De todas formas, la fijación es parcial puesto que en el discurso hablado entendemos directamente a quien habla porque está presente por medio de la ilocusión y la perlocución. En la escritura, como ya no está el autor, la comprensión del mensaje importa más de lo que dice el texto en sí. En el discurso hablado la referencia al mundo está presente por medio de los distintos actos. Al ser el mundo una cuestión humana, lo que hace la escritura es abrir mundos para ese lector. "La espiritualidad del discurso se manifiesta de nuevo a través de la escritura, que nos libera de la visibilidad y la limitación de las situaciones, abriendo un mundo para nosotros, es decir, dándonos nuevas dimensiones de nuestro ser-en-el-mundo" (Ricoeur, 1985, p. 53). Ricoeur también llama a esta situación como "la espiritualidad de la escritura", en la medida que no están presentes ni el autor, ni el acontecimiento en sí, ni siquiera el interlocutor, pero sí la variedad de lectores que pueden acceder a la obra. 
Las ciencias humanas, en su búsqueda del estudio de la de la acción significativa, según Ricoeur, tendrían cuatro elementos que se equipararían a las características del texto escrito. En principio, subyace la pregunta ¿Se puede fijar la acción humana, así como la escritura fija eso de lo que se habla? Ricoeur acude a una objetivación ${ }^{1}$ de la acción significativa, tal y como ocurre con la fijación de la escritura. De esta manera, se puede realizar una interpretación a partir de su estructura interna del habla, particularmente en el acto ilocutivo. Por otra parte, Ricoeur pone de la siguiente manera otra característica que equipara la dinámica del texto a la significación de la acción humana: "En la misma forma en que un texto se desprende de su autor, una acción se desprende de su agente y desarrolla consecuencias que le son propias" (Ricoeur, 1985, p. 57). Esto sucede porque la acción se puede escapar de quien la ejecuta y sustraerse a hechos distintos a los de la intención inicial del emisor. Ricoeur establece que se puede decir, en contra de este argumento, que es la historia la que definitivamente fija la acción. Pero contraargumenta y afirma que la acción humana se institucionaliza y, en consecuencia, se pierden los actores. En tercer lugar, la importancia de la acción excede el momento de su acontecimiento. Así como el texto escrito puede sobrepasar su momento histórico hacia nuevos mundos y nuevas interpretaciones, la acción significativa abre la puerta a otros significados derivados de su momento original a otros contextos sociales. En cuarto lugar, si el texto se refiere a múltiples lectores, así también lo puede hacer la acción humana, para que pueda estar abierta a distintas interpretaciones — no todas, claro está.

Al texto —nos dice Ricoeur- se puede llegar desde distintos ángulos, pero, si se pretende estar en el campo científico (social), no se puede caer en un relativismo donde toda interpretación es válida. Así pues, el filósofo francés es certero al afirmar lo siguiente:

Una interpretación debe ser no sólo probable, sino también más probable que otra [...] si bien es verdad que siempre hay más de una forma de interpretar un texto, no es verdad de todas las interpretaciones son iguales y que pueden ser asimiladas a las así llamadas "reglas empíricas". El texto es un campo limitado de interpretaciones posibles. (Ricoeur, 1985, p. 64)

Asimismo, la interpretación de la acción humana aplica a lo anterior. Para esto es necesario superar la famosa dicotomía de Dilthey: explicación y comprensión. Las dos pueden ser solidarias. Según esto, puede ser pertinente decir que se puede ir, por una parte, de la comprensión a la explicación:

La comprensión convoca la explicación apenas deja de existir una situación de diálogo, en la que el juego de las preguntas y las respuestas permite verificar la interpretación de una situación a medida que se desarrolla. En la situación de simple diálogo, explicar y comprender

1 No se debe entender objetivación a la manera de las ciencias positivas, sino en el sentido de la fijación que hace la escritura. 
se cubren, aproximadamente. Cuando no comprendo en forma espontánea, pido una explicación; la explicación que se me da me permite comprender mejor. (Ricoeur, 1985, p. 79)

El movimiento de interpretación también se puede dar en el sentido inverso, esto es, de la explicación a la comprensión. Acá Ricoeur, como suele ocurrir en muchos de sus planteamientos, trata de conciliar dos formas opuestas de acceso al texto, a tal punto de reconocer la validez de cada una en el acto de interpretación. Por un lado está la opción de lectura que aísla al texto del mundo circundante y se interpreta desde su interior; por otra parte se encuentra el surgimiento de nuevas referencias textuales derivadas de la propia lectura. En el primer caso subyace la necesidad de una actitud explicativa propia de la hermenéutica. No obstante, se puede decir que en este punto se explica el texto, pero aún está ausente la interpretación. Si la interpretación está ausente estaríamos ante un análisis meramente estructural, insuficiente para la hermenéutica ricoeuriana.

La comprensión se hace presente cuando hay una apropiación de quien hace la interpretación. Ricoeur matiza, teniendo presente los ataques de inconmensurabilidad de esta idea en el campo de las ciencias humanas, que esta apropiación no es una captación inmediatamente de la acción humana, sino que está mediada por el proceso de explicación. En otras palabras, la apropiación no es algo espontáneo, sino algo que surge de la explicación.

En resumen, las características de un texto escrito se pueden equiparar a las del acto de habla de la acción significativa. Por consiguiente, así como el texto escrito es susceptible de ser interpretado, también lo es la acción significativa de los fenómenos sociales. En consecuencia, se puede evidenciar que los procesos de interpretación hermenéutica, por lo menos desde Ricoeur, son plausibles para la investigación cualitativa en las ciencias humanas.

\section{Enfoque biográfico-narrativo}

Surge un problema conceptual en lo que concierne al momento de referirnos a lo que provisionalmente llamaremos lo biográfico y lo narrativo en la investigación cualitativa. Si bien los dos guardan similitudes, no pueden considerarse iguales. Esta línea difusa tiene que ver con la forma en que se hace el proceso de interpretación de una situación biográfica.

Por el momento, traemos a la discusión el llamado de atención que hace Bassi (2014) entre lo que él insiste en llamar método biográfico y método narrativo. Él evidencia que la distinción tiene que ver con la parte de la experiencia del sujeto que se estudia. Si el investigador pretende escoger la totalidad de la vida del sujeto, estamos en el campo de lo biográfico; si, por lo contrario, escogemos una parte de su vida, estamos hablando de lo narrativo. Aunque, como vemos, lo que está acá es algo muy similar a la distinción más difundida entre historia 
de vida y relato de vida dada por Denzin (1989). Él nombra como life story al relato de vida. Ahí se estudia la historia del sujeto tal y como él la ha contado. La historia de vida, life history, es la reconstrucción de la vida del sujeto a partir de distintas fuentes.

Bassi aclara que la diferencia se da más por una cuestión histórica, ya que, como muestra de manera exegética, ambos enfoques han sido desarrollados en tradiciones académicas separadas. Además, Bassi se arriesga a plantear que la investigación biográfica se enfoca en pocas personas, y la narrativa en múltiples.

Estamos de acuerdo con Bassi en que la división que él hace es provisional y discutible, por lo tanto, deducimos de esta afirmación que puede seguirse construyendo y debatiendo. Por lo tanto, nos arriesgamos a plantear que diferimos de una división tan tajante. Por un lado, no consideramos que lo biográfico y narrativo pueda ser definido por el número de personas que son estudiadas. Esta decisión depende del objeto de estudio, los fines y alcances de la investigación. Tampoco que lo biográfico y lo narrativo se diferencien según la porción de experiencia de vida escogida por los sujetos, puesto que lo que lo convierte en narrativo no es una cuestión de cantidad, sino la forma en que se interpretan y transcriben los resultados, tal y como se verá más adelante. Por otra parte, Bassi insiste en llamar método a la cuestión biográfica. Pese a esto, matiza lo siguiente:

Resulta complejo aislar los niveles epistemológicos, teóricos metodológicos, y técnicos en la investigación social. Así, parecería relativamente injusto hablar de "método biográfico" (o, para el caso, de "método narrativo" o "etnográfico") [...]. A pesar de ello, entiendo que es apropiado seguir usando el término método biográfico, mientras no se lo considere como algo que puede ser aislado de otros niveles, particularmente hacia arriba de la posición epistemológica de la que deriva y, "hacia abajo", de las técnicas que son pertinentes para sus planteamientos. (Bassi, 2014, p. 155)

Diferimos de esto último porque, si se quiere que lo biográfico no se le aísle de los componentes que él expone, y de otros, no se puede tipologizar como una historia de vida completa, sino que también, una biografía, puede ser una parte de la experiencia del sujeto. Así pues, ante la dificultad de definir de manera exacta lo biográfico, entonces es preferible hablar de un "enfoque biográfico", según lo que sustentaremos a continuación.

Con respecto a lo biográfico, Rojas (citado en Tarres, 2008) expone cómo Ferratori, aunque usa el término método biográfico, prefiere referirse a este como un enfoque. La razón de esta decisión se debe al ramillete de caminos que se abren a nivel investigativo al darle este nombre, pues no lo encasilla a una situación en particular. Más diciente aún, y que ilustra de mejor manera lo que queremos poner de manifiesto, es la definición que da Argüello (2014) al estudio biográfico. Si bien él se cuida en decir que al definirlo de manera general, corre el riesgo 
de enunciarlo con simplicidad, para lo que nos concierne, esto apoya la idea de nombrarlo como enfoque:

[...] un estudio biográfico es la construcción direccionada, analítica y sistemática de la historia de vida de una persona o de un colectivo, usando diversos tipos de documentos, según el caso, en el marco de un propósito específico de construcción de conocimiento, referido normalmente a variadas aplicaciones de las ciencias sociales. La densidad de esta definición nos permite inferir que la llamada "perspectiva biográfica" no implica simplemente un sistema de técnicas sino, ante todo, un territorio epistemológico con sus consecuentes plataformas de interpretación, dispositivos de operación, pautas de sistematización y modos de análisis. (p. 294)

En síntesis, un enfoque biográfico nos remite a la historia de vida de los sujetos. Esto es más amplio que una técnica y escapa a un encasillamiento conceptual. Por lo contrario, este enfoque está abierto a modificaciones según el contexto investigativo, pero que en esencia guarda el carácter común histórico de la historia o historias que se pretenden estudiar.

Cabe decir que las descripciones que abordan el enfoque biográfico coinciden en que no es un desarrollo reciente. Su gran despliegue se da en alrededor de 1920 a partir de los esfuerzos de la escuela de Chicago por darle importancia a los relatos orales en el campo de la sociología. No obstante, sus orígenes se hallan desde antes, en investigaciones en campos como la psicología o la antropología. El interés que ha adquirido en los últimos años tiene que ver con la coyuntura de rescatar los relatos micro del sujeto. "El reencuentro de la sociología con lo biográfico, entonces, no es más que el resultado de querer comprender dimensiones de la realidad social a un nivel micro. Es un nuevo 'retorno del sujeto' al análisis social y el reconocimiento de que el saber del hombre ordinario tiene valor sociológico" (Rojas, citado en Tarres, 2008).

Nótese que encontramos que acá no hay un uso de la palabra narrativo, y es por esto que surge la importancia de hablar de un enfoque biográfico-narrativo. Lo narrativo compone una forma de acceso a lo biográfico, e incluso una forma de contar lo biográfico en sí mismo.

Vamos a lo narrativo. ¿Qué hace a una investigación narrativa? ¿El que se acuda a fuentes narrativas? Si acudimos a las narraciones de un sujeto o sujetos, quiere decir que estamos ad portas de un estudio narrativo. Pero esto no dice nada aún, porque el enfoque biográfico también guarda esta característica. Los resultados de las narraciones pueden derivar en un análisis categorial, tal y como se puede percibir en la forma de abordar un informe biográfico, según lo plantea Desmarais en una serie de pasos técnicos para la comprensión de este enfoque. De este destacamos algunos que precisan lo que queremos ilustrar: 
4. Descomponer el texto en unidades de significado englobadas en un tema, constituyendo cada tema una ficha.

5. Crear categorías sustantivas para reunir las fichas-temas; estas categorías son próximas a los propósitos de las personas informadoras.

6. Para crear mega-categorías, retornar a los principales componentes teóricos del objeto de estudio señalados con anterioridad y establecer los puentes de relación.

7. Reconstruir el propósito de las personas informadoras escribiendo un texto que articule las fichas reagrupadas por categoría y megacategoría completándolo con los datos del perfil sociodemográfico. (Desmarais, 2009, p. 49)

Ahora observemos el matiz que se hace evidente en los siguientes puntos, de los cuales también destacamos algunos, acerca de la técnica de recogida de datos de un enfoque biográfico-narrativo, tal y como lo expone Bolívar²:

- Hermenéutica: se interesa por los significados, que son interpretados a partir de la observación y la voz (narración) de los agentes/actores. Se intentan conocer los hechos humanos a través de la experiencia humana, tal y como ha sido vivenciada.

- Naturalista: captar las realidades y acciones en la forma en que se presentan o suceden. La investigación biográfica, como los estudios de caso, se dirige a las situaciones particulares, individuos o eventos en su singularidad. Se busca comprender los valores, creencias y significados de las personas que están inmersas en la situación analizada.

- Dimensión temporal: la narrativa se relaciona específicamente con la comprensión humana del tiempo. Paul Ricoeur ha llegado a afirmar que el tiempo se hace tiempo humano en la medida en que se articula en un modo narrativo, y la narración alcanza su plena significación cuando se convierte en una condición de la existencia temporal. (2002a, pp. 562-563)

El matiz al cual nos referimos es el que concierne al diseño temporal, pues ya arroja luces a la cuestión precisa de lo narrativo. La pista nos dice que el relato se tiene en cuenta como la conformación temporal en el sentido existencial del mismo. Por lo tanto, el trato que se le da al relato no es el mismo que en otros enfoques. En lo narrativo emergen núcleos temporales, más que categorías precisas. Lo que se busca en la narración no es la construcción biográfica como tal, sino la comprensión de un fenómeno por medio de la narración. Si bien se

Los aportes de Bolívar a los estudios biográfico-narrativos se orientan al campo particular de la educación. 
busca comprender al sujeto, también el acontecimiento en el tiempo donde interviene. Según Bolívar (2002b), concretamente, la narración se entendería como

[...] la cualidad estructurada de la experiencia entendida y vista como un relato; por otro (como enfoque de investigación), las pautas y formas de construir sentido, a partir de acciones temporales personales, por medio de la descripción y análisis de los datos biográficos. (p. 6)

$\mathrm{Al}$ ser textos que parten de una experiencia directa con el mundo que compartimos, cuestión crucial en la investigación cualitativa, la interpretación tiene que pasar por una situación de diálogo con la narración. Esto, porque es el investigador el que conversa con el texto por medio de la narración que construye en el relato interpretado. De esta manera, consideramos que la escritura narrativa puede emerger.

La estructura narrativa aparece con el informe de investigación. Esto no quiere decir que otras formas cualitativas de acceso al fenómeno no tengan un contenido narrativo. Lo que se quiere poner de manifiesto es que el énfasis narrativo del informe hace que se pueda hablar de lo narrativo. Esto último porque "cuando desaparece el carácter narrativo en el informe, por un fuerte tratamiento categorial o analítico, la investigación ha dejado de ser narrativa" (Bolívar, 2002a, p. 566).

Huchim y Reyes (2013), basados en Bolívar (2001), evidencian que lo narrativo puede ser entendido desde tres puntos:

1. El fenómeno que se investiga: qué es el producto escrito o hablado.

2. El método como investigación: la forma como se construye y analiza ese fenómeno narrativo.

3. El uso que se le pueda dar a esa narrativa: ya sea mediante la reflexión biográfico-narrativa, o para impulsar cambios en las prácticas de formación en los docentes, por ejemplo, la evaluación de las competencias profesionales.

La investigación cualitativa en torno al enfoque biográfico-narrativo necesita de un fuerte talante interpretativo que se da por medio de la escritura en sí. Esto quiere decir que, a diferencia de otros informes cualitativos, el investigador debe tener una capacidad de escritura narrativa que le permita moverse entre la explicación, la comprensión y la narración. El resultado de este tipo de estudio casi que está obligado a hacer una narración de la narración. Como establece Bolívar

Una buena investigación narrativa no es sólo aquella que recoge bien las distintas voces sobre el terreno, o las interpreta, sino también aquella que da lugar a una buena historia narrativa, que es —en el fondo- el informe de investigación. Desde esta perspectiva, lo que en 
la investigación convencional se llama "explicación" no sería más que la mejor forma en que se organiza un relato para que sea comprensible y convincente. Lo biográfico singular se tiene que inscribir en un marco de estructura general, las narrativas de acción en una genealogía de contexto que las expliquen. (2002a, p. 565)

Por lo tanto, más que un enfoque metodológico, estamos ante una elección propia del objeto de estudio, que, al ser narrado, necesita de nuestra narración para ser explicado.

Según plantea Resendiz (citado en Tarres, 2008), el tema que cruza la situación metodológica en torno a lo biográfico y lo narrativo es el de la subjetividad, vista desde tres dimensiones. En primer lugar, como intento de lectura de lo social, desde los sujetos; en segundo lugar, en el sentido de la estrecha relación entre investigador y entrevistado, lo cual plantea desafíos particulares para dar validez y confiabilidad a la información, y, en tercer lugar, lo biográfico, como recurso para penetrar, explorar y comprender la subjetividad, los sentidos, las representaciones de los individuos sobre hechos, procesos y acontecimientos que nos interesa explorar y que forman parte de su historia personal (p. 138).

Lo anterior nos remite a tres subjetividades y escenarios. De la primera situación se puede decir que se evidencia que las realidades particulares de los sujetos nos pueden revelar situaciones sociales que son susceptibles de ser interpretadas para llevar a la comprensión de una realidad. La segunda sería un encuentro de subjetividades. Acá ya no es el investigador que manipula un experimento, sino que se considera como alguien que comparte la investigación del sujeto núcleo de su búsqueda de la comprensión social. La tercera situación sería una vuelta a la subjetividad del sujeto investigador, no desde una racionalidad cartesiana, sino como una forma de tenerse a sí mismo en cuenta para la investigación.

Queda entonces de manifiesto que lo que da el carácter narrativo al enfoque biográfico-narrativo es la forma en la que se lleva a cabo el proceso de interpretación. No basta con que el investigador acuda a una narración para que se pueda afirmar que está en este campo. Lo que de por sí establece el carácter narrativo es que en el proceso de escritura, el estilo en cuanto tal, evidencia esta estructura textual.

La técnica más difundida de acceso a la experiencia de los sujetos para el enfoque biográfico-narrativo son las entrevistas a profundidad para acceder a un relato de vida. En lo que queremos avanzar a continuación es qué ocurre cuando el investigador está inmerso en la interpretación de esta narración. Para esto volveremos a Ricoeur, teniendo en cuenta que es con él que establecimos más arriba la relación entre hermenéutica y ciencias sociales. Ahora queremos explicar el vínculo entre el enfoque biográfico-narrativo propio de la investigación cualitativa y la noción de narración del filósofo francés. 


\section{Interpretación del texto narrado y relato de vida}

Dos personas que no se han visto hace mucho tiempo se reencuentran. Empiezan a intercambiar experiencias acerca de su vida en el periodo que estuvieron separados. Tienen que hacer el esfuerzo de rememorar. Son demasiadas cosas para contar, así que se centran en las más significativas. Uno ya tiene familia, el otro ha viajado mucho durante su vida. En esas dos cosas parece basarse la conversación, en principio. Ellos si bien narran una experiencia, están narrándose a sí mismos como testigos de lo sucedido. La misma situación ocurre cuando se le pregunta a alguien qué hizo el día de ayer. Si ocurrió algo significativo se centrará en eso. Seguramente no dirá qué desayunó, almorzó o comió; qué tipo de vestimenta llevaba ese día, o la hora exacta en la que se levantó, puesto que no son datos relevantes. No obstante, se narra a sí mismo, a su propia experiencia pasada.

No es lo mismo narrar lo que hizo otra persona que narrarse. Cuando me narro puedo saber qué situación es significativa para mí. No ocurre lo mismo cuando narro al otro; no sé los núcleos significativos de esa experiencia. A no ser que estemos en un plano literario del narrador omnisciente, el hecho de narrar la experiencia de otro, esa experiencia que no se vive en primera persona, nos lleva a elegir arbitrariamente las acciones o hechos significativos de esa experiencia. ¿Pero qué ocurre cuando esa persona me narra su experiencia como ocurre en un enfoque biográfico-narrativo? A diferencia de la elección arbitraria cuando relatamos la experiencia del otro, cuando escucho esta narración en el plano de la investigación cualitativa, ya asumo la posición de intérprete.

Al solicitar a un narrador que nos relate su vida o parte de ella, además de la petición explícita de los contenidos que interesa investigar, existe una petición implícita: la de tomar una posición frente a lo que cuenta. El relato conlleva para el narrador una elección ineludible: optar por asumir o desconocer su posición respecto a su dicho (Cornejo, Mendoza y Rojas, 2008, p. 31).

Puedo hacer una lectura del otro, porque está poniendo su vida en la palabra. Acudo a él como texto. En este sentido, comprender al otro también es comprenderse, más aun

Comprenderse es comprenderse ante el texto y recibir de él las condiciones de un sí mismo distinto al yo que se pone a leer. Ninguna de las dos subjetividades, ni la del autor ni la del lector, tiene, pues, prioridad en el sentido de una presencia originaria de uno ante sí mismo. (Ricoeur, 2000, p. 18)

El autor del texto no es transparente, el texto tampoco y, mucho menos, el lector. Esto último quiere decir que el que lee y busca la comprensión no hace gala de una subjetividad poseedora de la vara mágica de la interpretación, sino que está sujeta a las mediaciones fuera del sujeto. Tampoco la subjetividad del autor 
presenta esta misma mecánica de descentramiento de la experiencia propia. Así pues ni lector, ni obra por sí misma permiten el acto de comprensión dada su "intrasparencia".

El texto tiene una doble situación: su estructura interna y el discurso que se puede hilar con su exterior. Por lo tanto, el trabajo del hermeneuta parte de la necesidad de ver que el texto dice algo desde su interior, pero que se conecta con su exterior, con el mundo.

[...] el lenguaje no constituye un mundo por sí mismo. Ni siquiera es un mundo. Por estar en el mundo y por soportar situaciones, intentamos orientarnos sobre el modo de la comprensión y tenemos algo que decir, una experiencia que llevar al lenguaje, una experiencia que compartir. (Ricoeur, 2002, p. 150)

La afirmación, narrar es narrarse, no puede llevarnos a asumir que debemos comprender al autor de la narración desde su propio texto, sino que la interpretación requiere superar el texto como discurso propio y exclusivo del autor. La propuesta hermenéutica de Ricoeur (1999) nos permite acercarnos a la forma en que se puede interpretar el relato de vida desde el enfoque biográfico-narrativo:

[...] para dar sentido al concepto de una historia de vida, no carecemos de instrumentos lingüísticos de carácter analítico. El relato es la dimensión lingüística que proporcionamos a la dimensión temporal de la vida [...]. La historia de una vida se convierte en una historia contada. (p. 340)

Lo que nos ayuda la lectura de Ricoeur es su acercamiento temporal tanto del relato como de la identidad del sujeto. Claramente un relato de vida no guarda la estructura narrativa concreta como la que alude Ricoeur cuando acude a la Poética de Aristóteles. Sin embargo, si quisiéramos comprender al sujeto que expresa el relato de vida como un personaje de una narración, cuya estructura temporal que remonta a un pasado, es la misma que propone la situación temporal del texto narrado, que a su vez se va desarrollando según el relato como persona.

Para Ricoeur existe una afinidad entre el relato de ficción y un relato histórico, puesto que personaje y persona guardan una estructura similar. Ambas carecen de un referente inmediato. La ficción literaria no carece de referencia pues tiene como correlato la realidad misma de la que se distancia, pero que toma como mímesis para su desarrollo. Lo mismo ocurre con el relato histórico. Este carece de un relato presente, que si bien es real, no es verificable dado su carácter de pasado. “¿Dónde se cruzan la referencia por huellas y la metafórica sino en la temporalidad de la acción humana? La historiografía y la ficción literaria, ¿no refiguran en común el tiempo humano al cruzar sobre él sus modos referenciales?" (Ricoeur, 2002, p. 155). Por esto, tanto el uno como el otro son similares puesto que guardan un carácter temporal que tiene referencias indirectas con lo que podemos llamar "real". Frente a esto, nos dice el filósofo francés: 
[...] el carácter común de la experiencia humana, señalado, articulado y aclarado por el acto de narrar en todas sus formas, es su carácter temporal. Todo lo que se cuenta sucede en el tiempo, arraiga en el mismo, se desarrolla temporalmente; y lo que se desarrolla en el tiempo puede narrarse. Incluso cabe la posibilidad de que todo proceso temporal sólo se reconozca como tal en la medida en que pueda narrarse de un modo o de otro. (Ricoeur, 2000, p. 3)

Es así que las ideas de Ricoeur también pueden ser consideradas para un relato de vida puesto que esta narración, aunque carece del referente inmediato al momento de ser leída e interpretado, tiene una referencia a la realidad que se quiere investigar.

Queremos insistir en el matiz que debemos darle a la relación entre las ideas del pensador francés y el enfoque biográfico narrativo. En este último, la narración se va hilando desde el mismo lector-investigador en su acto de interpretación, lo cual implica que el intérprete es actor dentro de la formación de la narración de quien narra para efectos de comprensión en el marco de un informe de investigación narrativo. El lector-investigador hace una comprensión de sí mismo necesaria para la comprensión del texto, y que está en el plano de la apropiación del lector del personaje propio del narración.

La mediación narrativa subraya, de ese modo, ese importante carácter del conocimiento de uno mismo que consiste en ser una interpretación de sí mismo. La apropiación de la identidad del personaje ficticio que lleva a cabo el lector es el vehículo privilegiado de esa interpretación. (Ricoeur, 1999, p. 15)

La propuesta de Ricoeur con respecto a la narración parte del hecho de que el sujeto tiene una identidad narrativa inherente a la función narrativa. Esto sugiere que el conocimiento de sí mismo "consiste en interpretarse a uno mismo a partir del régimen del relato histórico y del relato de ficción". (Ricoeur, 1999, p. 3). Pese a esto último, la narración por sí misma no es diáfana, la escritura por sí misma tampoco. Por lo tanto, la narración es susceptible de interpretación pues "lo que se ha de comprender en un relato no es en primer lugar al que habla detrás del texto, sino de aquello de lo que se habla, la cosa del texto, a saber, el tipo de mundo que la obra despliega de alguna manera delante del texto" (Ricoeur, 2002, p. 190).

La relación que existe entre el texto y el lector, y el mundo que se abre a su subjetividad a partir de la objetividad del texto, presenta, para el filósofo francés, una serie de fases que intervienen en la interpretación de la narración. La comprensión de lo narrado no se da de una manera directa, pero tampoco indirecta. Más bien, se puede decir que se mezclan entre la narración, el lector y el mundo, donde la interpretación es transversal a estos. 
La teoría de la triple mimesis de la narración de Ricoeur evidencia que esta tiene una situación estructural con respecto a la formación de oraciones, pero es la referencia a la acción la que da un significado más amplio. La estructura de la narración no se excluye del análisis de la acción pues a partir de la identificación de una u otra es que se pueden hallar, en principio, las características de una narración. "Comprender una historia es comprender a la vez el lenguaje del 'hacer' y la tradición cultural de la que procede la tipología de las tramas" (Ricoeur, 2004, p. 119).

Otra forma de la estructura narrativa tiene que ver con la mediación simbólica que se relaciona con el cúmulo cultural del relato. Lo anterior tiene su resolución comprensiva en las estructuras temporales que subyacen a la narración. Estas estructuras las entiende Ricoeur desde el concepto de intratemporalidad del Heidegger de Ser y tiempo.

Ricoeur ve en la intratemporalidad, el tiempo cotidiano, una posibilidad para explicar la estructura temporal de la narración. Esta no se relaciona con una sucesión de ahoras, sino con la facticidad de la narración. En síntesis, "la primera mímesis de la narración, imitar o representar la acción es, en primer lugar, comprender previamente en qué consiste el obrar humano: su semántica, su realidad simbólica, su temporalidad" (Ricoeur, 2004, p. 130). Esta primera mímesis vendría a ser la precomprensión del texto narrativo. La segunda mimesis, que para Ricoeur cobra una relevancia porque es su aporte para vincular o mejor, mediar entre la primera y la tercera mimesis, cobra forma en la trama misma del relato. Media en tres sentidos. Por un lado, entre los acontecimientos particulares y el todo de la narración; por el otro, es integradora de las múltiples situaciones de la historia; y en tercer lugar, presenta el carácter temporal de la narración. Esta última, a su vez, es cronológica porque da continuidad a los hechos, y no cronológica pues hace presente la historia como un todo. La tercera mímesis realiza un intersección entre el mundo del texto y el mundo del lector. También habría entonces una circularidad entre las tres mímesis ${ }^{3}$.

El lector que accede a la construcción de la trama narrativa puede presentar un problema al momento de hallar vacíos en esta. Por ejemplo, la novela que rompe la estructura temporal tradicional o que acude a juegos gramaticales que fuerzan al lector, a un punto tal de tener que enfrentarse a la obra con la necesidad de ser él quien la reconstruya. En el tipo de narración a la que nos enfrentamos en un relato de vida desde un enfoque biográfico-narrativo ocurre el mismo inconveniente, puesto que hay lagunas en la narración del sujeto participe de la investigación. Por eso, el papel del investigador, si hacemos la analogía con esta propuesta de la estructura narrativa del texto, consiste en tener presente que la comprensión es la búsqueda para darle sentido a la narración misma cuando esta lo requiera.

3 Este no es del todo el círculo de la comprensión de Gadamer. Acá tenemos el componente temporal de la narración, lo cual, de por sí, genera un matiz distinto. El círculo hermenéutico narrativo no debe entenderse como un círculo vicioso de la comprensión; más bien, es una interpretación que depende de los niveles que se van dando a medida que se repite el proceso de comprensión, en el sentido de una espiral. 
En resumen, un proceso de estudio empírico en ciencias sociales que tenga como núcleo la búsqueda de la comprensión de una narración, que a su vez tenga en cuenta el carácter temporal como el que evidencia el filósofo francés, permite que nos acerquemos a la comprensión con las herramientas que permitan situarnos como intérpretes de ese texto. Pero si le sumamos que, desde un enfoque biográfico-narrativo, esa narración como discurso hablado la convertimos a su vez en una narración escrita, esto supone que ese proceso de escritura es la puesta en marcha de la interpretación del texto. Según esto, los componentes de este enfoque para la investigación cualitativa serían: Escuchar, transcribir y escribir, con la interpretación como transversal a todo el proceso.

Por esto último, se sugiere que es la mímesis II la que nos permite como investigadores ir en un sentido interpretativo de un texto que nos depara la necesidad de tener presente todas las variables del proceso para dar cuenta de una interpretación que nos acerque a una verdad (Gadamer) o a una interpretación reflexiva del texto (Ricoeur). Por esto, la narración cumple un doble sentido en una investigación cualitativa como la que traemos a colación: por un lado, la narración es el fenómeno en sí a comprender; por el otro, es la interpretación que se convierte en narración como forma de acceso a la compresión de lo narrado.

La narración propone la identidad del sujeto, que a su vez es una identidad narrativa que no es estática, sino que está mediada por los niveles de la espiral interpretativa. Por consiguiente, para la investigación cualitativa, esto nos permite entender que lo que encontramos ahí es un proceso continuo de estructuración de la identidad que permite entrar la alteridad del otro, al mismo tiempo que permite el acto de interpretación de la narración. Esto conlleva a que, como lectores-investigadores de la narración, debemos salirnos de nuestros conceptos de mundo establecidos por nuestra propia experiencia para poder acceder al texto.

Así pues, si nos remitimos a la mímesis, es la mímesis III la que presenta esa relación del lector con el texto. Esto, traducido a una relación investigativa de interpretación de relatos de vida querría decir lo siguiente:

El narrador, por su parte, no puede poseer el sentido, irreducible a la conciencia que tiene, estando tan implicado, "corporeizado" en su propia experiencia, en lo que cuenta. En el relato el sujeto deviene su propio objeto de conocimiento, para lo cual debe distanciarse, desdoblarse simbólicamente. El narratario, en cambio, debe acercarse a las vivencias del narrador, abrirse a su lenguaje cotidiano, salir de sus propios sistemas conceptuales. Estos desplazamientos recíprocos e inversos (de distanciamiento teórico e implicación práctica) permiten la creación de un espacio y de un sistema de comunicación, de una nueva unidad, donde una parte de vida encuentra sus conceptos y unos conceptos encuentran vida. (Cornejo, Mendoza y Rojas, 2008, p. 31) 
Como se presenta en la relación lector y texto, donde una intimidad los acerca desde el interior del primero, con el exterior del segundo, ambos mediados por el mundo, en el caso del narratario y el narrador encontramos ese diálogo entre sujeto y sujeto. Claro está que acá el movimiento es doble, a diferencia de la primera relación. Interpreto el texto narrado cuando ya está transcrito, no la situación oral en sí, por lo tanto, nos encontramos de todas formas frente a la misma relación entre lector y texto que se presenta en la propuesta de Ricoeur.

\section{Consideraciones finales}

La hermenéutica va más allá de una relación metodológica con las ciencias humanas. Este campo lleva implícita una relación ética con la investigación cualitativa. Conceptos que establecen relaciones entre el yo-tu (Gadamer), el otro que irrumpe desde nuestra exterioridad (Levinas), la reciprocidad entre el yo y el otro para pensar el nosotros (Ricoeur) son conceptos claves para la perspectiva hermenéutica.

Pensar las ciencias humanas desde la hermenéutica significa abordarlas no solamente como una forma de acceder a un problema de investigación, sino una manera de concebir la relación investigativa entre quien investiga y el núcleo de significados que se busca comprender. Centrar la hermenéutica desde un tipo de desarrollo metodológico desconoce los avances que se han dado al interior de esta corriente filosófica en torno a la alteridad (Gama, 2009).

El acto investigativo desde un presupuesto hermenéutico entiende que la relación sujeto-objeto de las ciencias empírico-analíticas se diluye cuando se comprende que el objeto de investigación es un otro que puedo ser yo mismo. "La experiencia hermenéutica, al interior de un paradigma de investigación cualitativo, implica en primera instancia un proceso de formación del ser que investiga y simultáneamente un proceso de traducción de las estructuras de sentido" (González, 2011). La compresión e interpretación de un texto desde un enfoque biográfico-narrativo lleva implícito el proyecto hermenéutico de la alteridad ${ }^{4}$.

La reconstrucción biográfica emerge esencialmente de una persona y de su testimonio, ya sea oral u escrito, y de su interacción con el que lo retoma, interpreta y rehace (aún cuando este sea el mismo protagonista de los hechos que asume el rol de escritor como en el caso de las autobiografías), de modo que el juego de intersubjetividades va a ser una dinámica inherente y permanentemente presente. Igualmente emerge un mecanismo enmarañado, complejo, dinámico, selectivo y efectivo, cual es la memoria (Sanz, 2005).

4 Queremos guardar distancia de las críticas o debates en torno a los conceptos yo, tú, él y nosotros, que impregnan la discusión fenomenológico hermenéutica, ya que lo que nos interesa traer a colación es que en el acto de lectura de una narrativa existe una etapa de alteridad con respecto al texto. 
El investigador es un sujeto que quiere comprender un sujeto. Se vincula con él en una realidad compartida. No obstante, necesita de un alejamiento para poder realizar el acto de comprensión.

En el caso de Ricoeur, su noción de texto es amplia pues abarca distintas situaciones humanas. Se puede decir que es primariamente texto cuando queda en el campo escrito. De acá que el enfoque biográfico-narrativo sea también coincidente con estos planteamientos hermenéuticos puesto que al acto de escritura de lo hablado es vital para el proceso de interpretación.

Por esto último el relato de vida puede ser considerado una obra, tal y como lo plantea Ricoeur, puesto que, por un lado, debe tener una composición interna que permite hallar el sentido de lo que se lee; por otra parte, está la pertenencia a un género, que por más original que sea el escrito, se le permite vincularlo a una tipología textual. En tercer lugar está el estilo individual que le imprime quien está revelando el mensaje.

Siguiendo estos parámetros, podemos decir que un relato de vida está en el campo de la narración, teniendo en cuenta que está compuesta, por un sentido (composición) y su estructura permite llevarlo a esta tipología textual, y claro, todos los individuos son diferentes e imprimen su estilo particular a la narración. Es decir, si queremos interpretar algo debemos tener presente su estructura, pero al mismo tiempo excederla, para acceder al referente de la relación entre la obra y el mundo. De esta manera, no estaríamos hablando de un simple escrito.

En el caso particular de la interpretación de relatos de vida, se dan movimientos adicionales a los de la lectura de una obra literaria. Estos movimientos se dan a partir de la dinámica cuando el investigador escucha y dialoga con el sujeto o sujetos núcleo de la investigación. El primer movimiento es la transcripción del lenguaje hablado al plano escrito. En segundo lugar, después la lectura interpretativa del investigador que quiere interpretar eso transcrito. Este movimiento que proponemos se evidencia en lo que afirma Bolívar a continuación:

El investigador se convierte en aquel que construye y cuenta la historia (researcher-storyteller) por medio de un relato. La tarea investigadora consiste en observar los acontecimientos y personas. solicitando que los agentes cuenten sus propias historias y trayectorias acerca de los hechos/acciones solicitados por el investigador y, a partir de su análisis e interpretación, construir nuevas historias/relatos, que serán leídas por el público lector. La investigación narrativa es un proceso, complejo y reflexivo, de mutación de los textos del campo a los textos para el lector. El investigador recrea los textos, de modo que el lector pueda experienciar las vidas o acontecimientos narrados. Vivir y revivir, contar y recontar historias forma, pues, parte del trabajo, en un proceso de dar significado a la experiencia (Bolívar, 2002a, p. 561).

El investigador es un narrador de lo narrado, y que hila lo observado y escuchado desde una posición comprensiva que le permita acceder a la interpretación del 
fenómeno. Ese doble movimiento del que hablamos: es un re-narrar lo narrado, para sacar a la luz la narración esencial. Los sujetos pueden ser interpretados como textos. El carácter temporal de la narración configura al sujeto como personaje, lo cual tiene consecuencias interpretativas. Interior del texto narrado e investigador son cruciales para la interpretación en la investigación cualitativa.

\section{$\mathbf{R}_{\text {eferencias }}$}

Argüello, A. (2014). La perspectiva biográfica de la investigación educativa. Una mirada a sus antecedentes, tendencias y posibilidades. Estudios Pedagógicos, 40(1), 293-308. Recuperado de http://www.scielo.cl/pdf/estped/v40n1/ art18.pdf

Ávila, R. (2012). La tarea hermenéutica de las ciencias humanas. Signo y Pensamiento, 30(60), 44-60. Recuperado de http://revistas.javeriana.edu.co/ index.php/signoypensamiento/article/view/2409

Almario, O. y Ruiz, M. A. (2008). El giro hermenéutico de las ciencias sociales y humanas. Diálogo con la sociología. Medellín: Universidad Nacional de Colombia.

Ángel, D. (2011). La hermenéutica y los métodos de investigación en las ciencias sociales. Revista Estudios filosóficos, (44), 9-37. Recuperado de http://www. scielo.org.co/pdf/ef/n44/n44a02.pdf

Cuartas, J. (2010). Hermenéutica en acción. Cali: Universidad del Valle.

Bassi, J. E. Hacer una historia de vida: decisiones claves durante el proceso de investigación. Athenea Digital. Revista de Pensamiento e Investigación Social, 14(3), 129-170. Recuperado de http://www.redalyc.org/articulo. oa?id=53732540006

Betancur, M. C. (2008). La necesidad de generalidad en las ciencias sociales. Revista Praxis filosófica, (27), 195-202. Recuperado de http://www.redalyc. org/articulo.oa?id=209014644011

Bolívar, A., Segovia, D. y Fernández, M. (2001). La investigación biográfico-narrativa en educación. Enfoque y metodología. Madrid: Muralla.

Bolívar, A. (2002a). El estudio de caso como informe biográfico-narrativo. Revista Arbor, 171(675), 559-578. DOI: 10.3989/arbor.2002.i675.1046

Bolívar, A. (2002b). ¿De nobis ipsis silemus?: epistemología de la investigación biográfico-narrativa en educación. Revista Electrónica de Investigación Educativa, 4(1). Recuperado de http://redie.uabc.uabc.mx/vol4no1/contenido-bolivar.html 
Cornejo, M., Mendoza, F. y Rojas, R. (2008). La investigación con relatos de vida: pistas y opciones del diseño metodológico. Revista Psykhe, 17(1), 29-39. Recuperado de http://www.scielo.cl/pdf/psykhe/v17n1/art04.pdf

Denzin, N. (1989). Interpretative biography. Qualitative Research Methods (vol. 17). Newbury Park: Sage.

Desmarais, D. (2009). El enfoque biográfico. Cuestiones Pedagógicas, (20), 27-54. Recuperado de http://institucional.us.es/revistas/cuestiones/20/art_02.pdf

Flores Galindo, M. (2009). Epistemología y hermenéutica: entre lo conmensurable y lo inconmensurable. Cinta de Moebio, (36), 198-211. Recuperado de http//:www.moebio.uchile.cl/36/flores.html

Gadamer, H. G. (1977). Verdad y método. Salamanca: Sígueme.

Gama, L. (2009). El lugar del otro en las ciencias humanas hermenéuticas -y algunas perspectivas para América Latina. Nómadas, (31), 125-137. Recuperado de http://www.redalyc.org/articulo.oa?id=105112061009

González, E. M. (2011). Sobre la experiencia hermenéutica o acerca de otra posibilidad de construcción del conocimiento. Discusiones Filosóficas, 18(12), 125-143. Recuperado de: https://goo.gl/7fk0Kl

Grondin, J. (2009). El legado de la hermenéutica. Santiago de Cali: Editorial Universidad del Valle.

Herrera, J. D. (2009). La comprensión de lo social. Horizonte hermenéutico de las ciencias sociales. Bogotá: Cinde.

Huchim, D. y Reyes, F. (2013). La investigación biográfico-narrativa, una alternativa para el estudio de los docentes. Revista Actualidades Investigativas en Educación, 13(3) 1-27. Recuperado de http://www.redalyc.org/ pdf/447/44729878019.pdf

Molano, J. (2007). Las ciencias sociales como integración de saberes en la dimensión humana. Revista Tábula Rasa, (7), 275-303. Recuperado de: http://www. scielo.org.co/scielo.php?script=sci_arttext\&pid=S1794-24892007000200013

Ricoeur, P. (1985). Hermenéutica y acción. Buenos Aires: Docencia.

Ricoeur, P. (1999). Historia y narratividad. Barcelona: Paidós.

Ricoeur, P. (2000). Narratividad, fenomenología y hermenéutica. Análisis, (25), 189-207. Recuperado de http://www.raco.cat/index.php/analisi/article/ viewFile/15057/14898

Ricoeur, P. (2002). Del texto a la acción. Ensayos de hermenéutica II. México D. F.: Fondo de Cultura Económica. 
Ricoeur, P. (2004). Tiempo y narración: configuración del tiempo en el relato histórico. México D. F.: Siglo XXI.

Sanz, A. (2005). El método biográfico en investigación social: potencialidades y limitaciones de las fuentes orales y los documentos personales. Revista Asclepio, 57(1) 99-115. DOI: 10.3989/asclepio.2005.v57.i1.32

Scivoletto, G. (2012). La fundación práctica de la teoría desde el punto de vista hermenéutico-trascendental. Revista Praxis Filosófica, (34), 149-163. Recuperado de http://www.scielo.org.co/pdf/pafi/n34/n34a09.pdf

Schütz, A. (1972). La construcción significativa del mundo social: introducción a la sociología comprensiva. Barcelona: Paidós.

Tarres, M. L. (2008). Observar, escuchar y comprender. Sobre la tradición cualitativa en la investigación social. México D. F.: Porrúa. 